\title{
Robust Sliding Mode Fuzzy Control of a Car Suspension System
}

\author{
Ayman A. Aly \\ Mechatronics Section, Department of Mechanical Engineering, Faculty of Engineering, Assiut University, 71516, \\ Assiut, Egypt; \\ Currently: Mechatronics Section, Department of Mechanical Engineering, Faculty of Engineering, Taif University, \\ P.O. Box 888, Al-Haweiah, Saudi Arabia, \\ E-mail:draymanelnaggar@yahoo.com
}

\begin{abstract}
Different characteristics can be considered in a suspension system design like: ride comfort, body travel, road handling and suspension travel. No suspension system can optimize all these parameters together but a better tradeoff among these parameters can be achieved in active suspension system.
\end{abstract}

Objective of this paper is to establish a robust control technique of the active suspension system for a quartercar model. The paper describes also the model and controller used in the study and discusses the vehicle response results obtained from a range of road input simu lations. A comparis on of robust suspension sliding fuzzy control and passive control is shown using MATLAB simulations.

Index Terms - Vehicle Dynamics, Active Suspension System, Quarter-Car Model, Sliding Fuzzy Control

\section{Introduction}

The purpose of a car suspension is to adequately support the chassis, to maintain tire contact with the ground, and to manage the compromise between passenger comfort and vehicle road handling, which is important for the safety of the ride. Generally, there are three types of suspension systems, namely, passive, semi-active and active suspensions.

Passive suspensions can only achieve good ride comfort or good road holding since these two criteria conflict each other and necessitate different spring and damper characteristics. While semi-active suspense with their variable damping characteristics and low power consumption, on systems offer a considerable improvement [1-2].

A significant improvement can be achieved by using of an active suspension system, which supplies a higher power from an external source to generate suspension forces to achieve the desired performance. The force may be a function of several variables which can be measured or remotely sensed by various sensors, so the flexibility can be greatly increased.
With rapid advances in electronic technologies [3], the development of design techniques for the synthes is of active vehicle suspension systems has been an active area of research over the last two decades to achieve a better compromise during various driving conditions, [4-9].

Studies have been done based on Linear Gauss Quadratic regulator, such as references [10-12]. Linear Gauss Quadratic method has mature theory base and control algorithm, thus it is widely used in suspension control. It should be pointed out that the design and synthesis of active suspensions can be approached from many ways: Modal analysis, as in [13]; bond graph modeling methodologies, as in reference [14]; fuzzy logic, such as in [15], while each of these approaches can bring some useful perspectives, the present paper will focus on the applications of robust control techniques, and the following work will constitute the trends of the robust system structure and performance potentials.

The aim of this paper is to develop the control algorithms, which can achieve comfort and good handling quality without excessively degrading the body and axle working space.

This paper is organized as follows. In section II, the dynamics of a quarter-car suspension system is explained. Optimal control is designed in section III. Simulations are presented in section IV. At the end, the paper is concluded in section $\mathrm{V}$.

\section{A Quarter-Car Suspension System}

A car suspension system is the mechanism that physically connects the body of the car to their wheels, in other word suspension system isolates the car body from road disturbances and inertial disturbances as sociated with cornering and braking or acceleration.

Figs. (1, 2) illustrates the quarter-car model of a passenger car that most commonly used for controller design studies of active suspensions [16]. The equations of motion for the car model in the state equation are represented by: 


$$
\begin{aligned}
& \mathrm{m}_{\mathrm{b}} \ddot{\mathrm{z}}_{\mathrm{b}}=\mathrm{f}_{\mathrm{a}}-\mathrm{k}_{1}\left(\mathrm{z}_{\mathrm{b}}-\mathrm{z}_{\mathrm{W}}\right)-\mathrm{c}_{\mathrm{S}}\left(\dot{\mathrm{z}}_{\mathrm{b}}-\dot{\mathrm{z}}_{\mathrm{w}}\right) \\
& \mathrm{m}_{\mathrm{W}} \ddot{\mathrm{z}}_{\mathrm{W}}=-\mathrm{f}_{\mathrm{a}}+\mathrm{k}_{1}\left(\mathrm{z}_{\mathrm{b}}-\mathrm{z}_{\mathrm{W}}\right)-\mathrm{k}_{2}\left(\mathrm{z}_{\mathrm{w}}-\mathrm{z}_{\mathrm{r}}\right)
\end{aligned}
$$

with the following specifications of the suspension systemare given in Table 1:

Table 1: quarter car parameters

\begin{tabular}{|l|c|l|}
\hline \multicolumn{1}{|c|}{ Parameters } & Symbols & Quantities \\
\hline Body mass & $\mathrm{m}_{\mathrm{b}}$ & $250 \mathrm{~kg}$ \\
\hline Wheel mass & $\mathrm{m}_{\mathrm{w}}$ & $50 \mathrm{~kg}$ \\
\hline Stiffness of the body & $\mathrm{K}_{1}$ & $16 \mathrm{kN} / \mathrm{m}$ \\
\hline Stiffness of the wheel & $\mathrm{K}_{2}$ & $160 \mathrm{kN} / \mathrm{m}$ \\
\hline Stiffness of the damper & $\mathrm{C}_{\mathrm{s}}$ & $1.5 \mathrm{kN} . \mathrm{s} / \mathrm{m}$ \\
\hline
\end{tabular}

To transform the motion equations of the quarter car model into a space state model, the following state variables are considered:

$$
\underline{X}=\left[X_{1}, X_{2}, X_{3}, X_{4}\right]^{T}
$$

where $\mathrm{x}_{1}$ is body displacement $=\mathrm{z}_{\mathrm{b}}-\mathrm{Z}_{\mathrm{w}}, \mathrm{x}_{2}$ is wheel displacement $=\mathrm{Z}_{\mathrm{w}}-\mathrm{Z}_{\mathrm{r}}, \mathrm{x}_{3}$ absolute velocity of the body $=$ $\dot{\mathrm{z}}_{\mathrm{b}}$, and $\mathrm{x}_{4}$ absolute velocity of the wheel $=\dot{z}_{w}$.

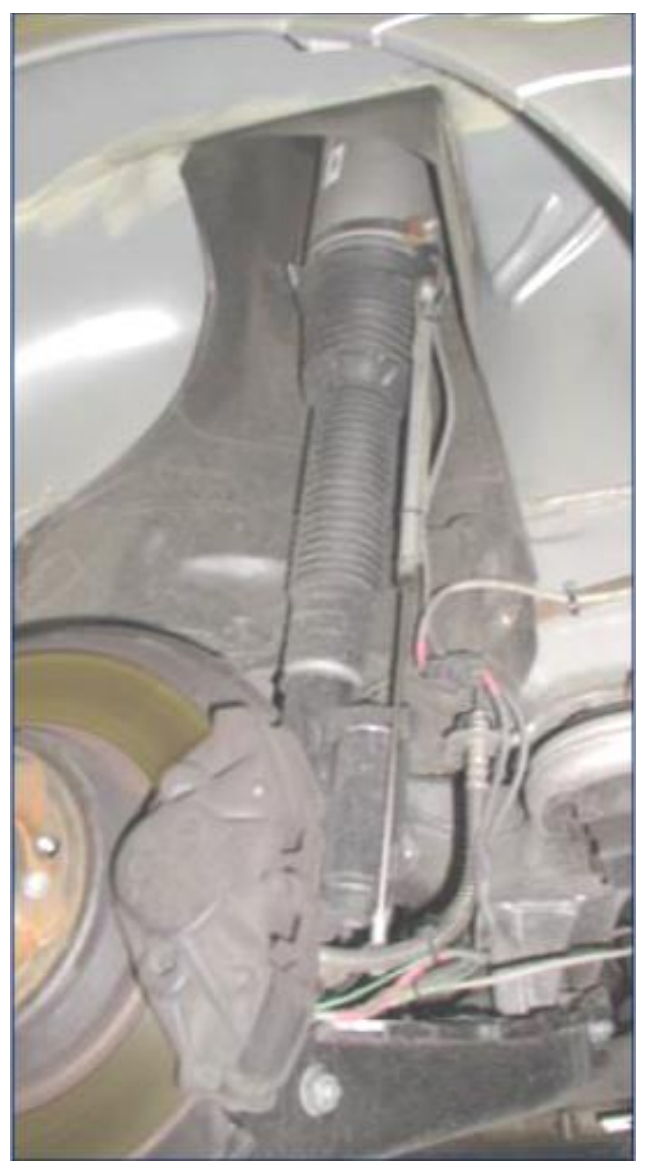

Fig. 1: quarter car model
Then the motion equations of the quarter car model for the active suspension can be written in state space form as follows:

$$
\underline{\dot{\mathrm{x}}}=\mathrm{A} \cdot \underline{\mathrm{x}}+\mathrm{B} \cdot \underline{\mathrm{a}}+\underline{\mathrm{F}} \cdot \underline{\mathrm{r}}
$$

with

$$
A=\left[\begin{array}{cccc}
0 & 0 & 1 & -1 \\
0 & 0 & 0 & 1 \\
-\frac{k_{1}}{m_{b}} & 0 & -\frac{c_{s}}{m_{b}} & \frac{c_{s}}{m_{b}} \\
\frac{k_{1}}{m_{w}} & -\frac{k_{2}}{m_{w}} & \frac{c_{s}}{m_{w}} & -\frac{c_{s}}{m_{w}}
\end{array}\right], B=\left[\begin{array}{c}
0 \\
0 \\
\frac{1}{m_{b}} \\
-\frac{1}{m_{w}}
\end{array}\right]
$$

and

$$
F=\left[\begin{array}{c}
0 \\
-1 \\
0 \\
0
\end{array}\right]
$$

where $\mathrm{f}_{\mathrm{a}}$ : control force, $\mathrm{z}_{\mathrm{r}}$ : road input displacement.

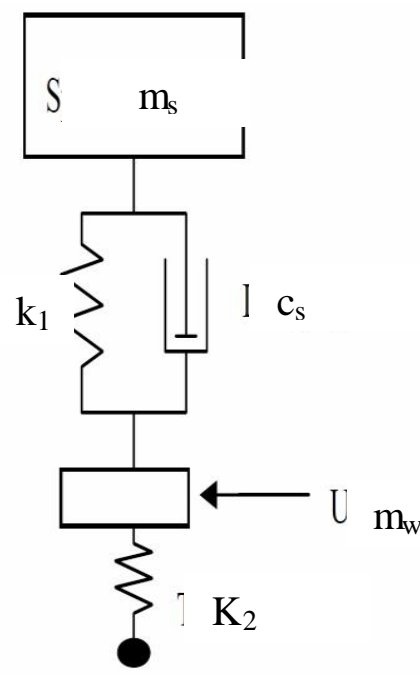

Fig. 2: 2 DOF model

\section{Suspension Control Development}

Fuzzy control systems are rule-based or knowledgebased systems, which have a set of fuzzy IF-THEN rules representing a control decision mechanis $m$ to adjust the certain effect coming from the system. Fuzzy controller have succeeded in many practical control problem that the conventional theories have difficulties to deal with. Therefore, the fuzzy control theory was used in this paper. Fig. 3 shows the rule table membership functions of the fuzzy controller. 


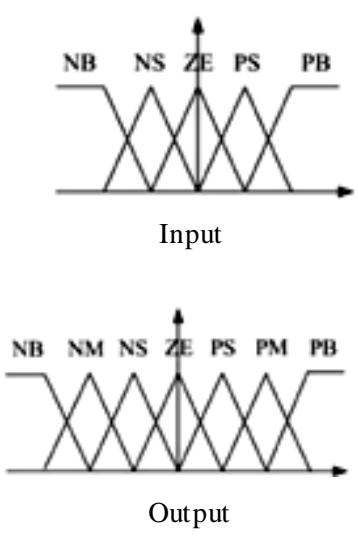

\begin{tabular}{|c|c|c|c|c|c|}
\hline$\Delta S^{A}$ & $\mathrm{NB}$ & $\mathrm{NS}$ & $Z E$ & $P S$ & $P B$ \\
\hline$N B$ & $Z E$ & PS & PM & PM & PB \\
\hline NS & NS & ZE & PS & PS & PM \\
\hline$Z E$ & NM & NS & ZE & PS & PM \\
\hline$P S$ & NM & NS & NS & ZE & PS \\
\hline$P B$ & NB & NM & NM & NS & ZE \\
\hline
\end{tabular}

Fig. 3: Membership functions and rule table of fuzzy control

Fuzzy control has been proposed to tackle the problem of car suspension for the unknown environmental parameters. However, the large amount of the fuzzy rules makes the analysis complex. Some researchers have proposed fuzzy control design methods based on the sliding-mode control (SMC) scheme. Since only one variable is defined as the fuzzy input variable, the main advantage of the FSMC is that it requires fewer fuzzy rules than FC does. Moreover, the FSMC system has more robustness against parameter variation. Although FC and FSMC are both effective methods, their major drawback is that the fuzzy rules should be previously tuned by timeconsuming trial-and-error procedures.

Traditional SMC is representing the simpler form of the robust control. Since the system is of the first order, the switching function is selected as:

$$
s=\lambda-\lambda_{r}
$$

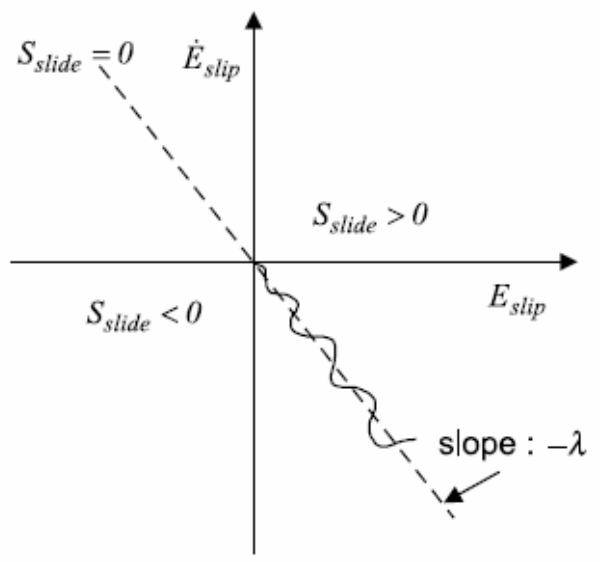

Fig. 4: Phase plane of sliding mode control
Where $\lambda_{\mathrm{r}}$ is the reference input wheel slip. The sliding motion occurs when state $\left(\lambda_{r}, \dot{\lambda}_{r}\right)$ reaches subspace (a point in this case) defined by $s=0$. (see Fig.4 )

The control that keeps the state on the switching subspace is called the equivalent control. Thedynamics in sliding mode can be written as

$$
\dot{s}=0
$$

It can be shown that,

$$
S\left(x_{1}, x_{2}\right)=x_{2}+\lambda x_{1}, \lambda>0
$$

For the convergence conditions:

$$
U_{e q}=-L^{-1}\left[a_{1} x_{1}+\left(a_{2}+\lambda\right) x_{2}\right]
$$

where:

$\mathrm{a}_{1}:-\mathrm{k}_{\mathrm{s}} / \mathrm{M}_{\mathrm{s}}$
$\mathrm{a}_{2}:-\mathrm{b}_{\mathrm{s}} / \mathrm{M}_{\mathrm{s}}$

$\mathrm{L}$ : a gain of the control related to $\mathrm{M}_{\mathrm{s}}$

$\mathrm{L}=\sqrt{b_{\min } n}, b_{\max }$

$b_{\min }$ : empty vehicle

$b_{\max }$ : loaded vehicle

Ugguarantee convergence towards the sliding surface and is defined by following form:

$$
U_{g}=-L^{-1} K \cdot \operatorname{sgn}(S)
$$

$K$ is satisfying the sliding condition. When the system state is on the switching subspace, the hitting control is zero. The hitting control is determined by the following reaching condition, where $\eta_{s}$ is a strictly positive design parameter:

$$
s \dot{s} \leq-\left.\eta_{s}\right|_{s} \mid
$$

Assume there are $\mathrm{n}$ rules in a fuzzy knowledge base and each of them has the following form:

$$
\text { Rule i: if } s \text { is } S_{i} \text { the } u \text { is } \alpha_{i}+\beta_{i} s
$$

Where $\mathrm{u}$ is the output variable of the fuzzy system; $\mathrm{S}$ are the membership functions and $\left(\alpha_{i}, \beta_{i}\right)$ are singleton control actions. By the method of center of gravity:

$$
u=\sum_{i=1}^{n} w_{i}\left(\alpha_{i}+\beta_{i} s\right) / \sum_{i=1}^{n} w_{i}
$$

where $w_{i}$ is the firing weight of the $i^{\text {th }}$ rule, $\alpha=\left[\alpha_{1}, \ldots\right.$, $\left.\alpha_{n}\right]^{T}$, and $\beta=\left[\beta_{1}, \ldots, \beta_{n}\right]^{\mathrm{T}}$

In order to fulfill the objective of designing an active suspension system i.e. toincrease the ride comfort and road handling, there are three parameters to be observed 
in the simulations. The three parameters are thewheel deflection, dynamic tire load and car body acceleration. For definition of the allowable limits of car body acceleration, there is a frequency domain where human beings are most sensitive to vibration (hu man sensitivity band). Figure (5) gives a measured result from a report of ISO/DIS 5349 \& ISO 2631 - 1978, which shows the human endurance limit to frequency band to vertical acceleration is $4 \sim 8 \mathrm{~Hz}$, which means that for the purpose of improving the ride comfort the car body acceleration gain should be in this range [17].

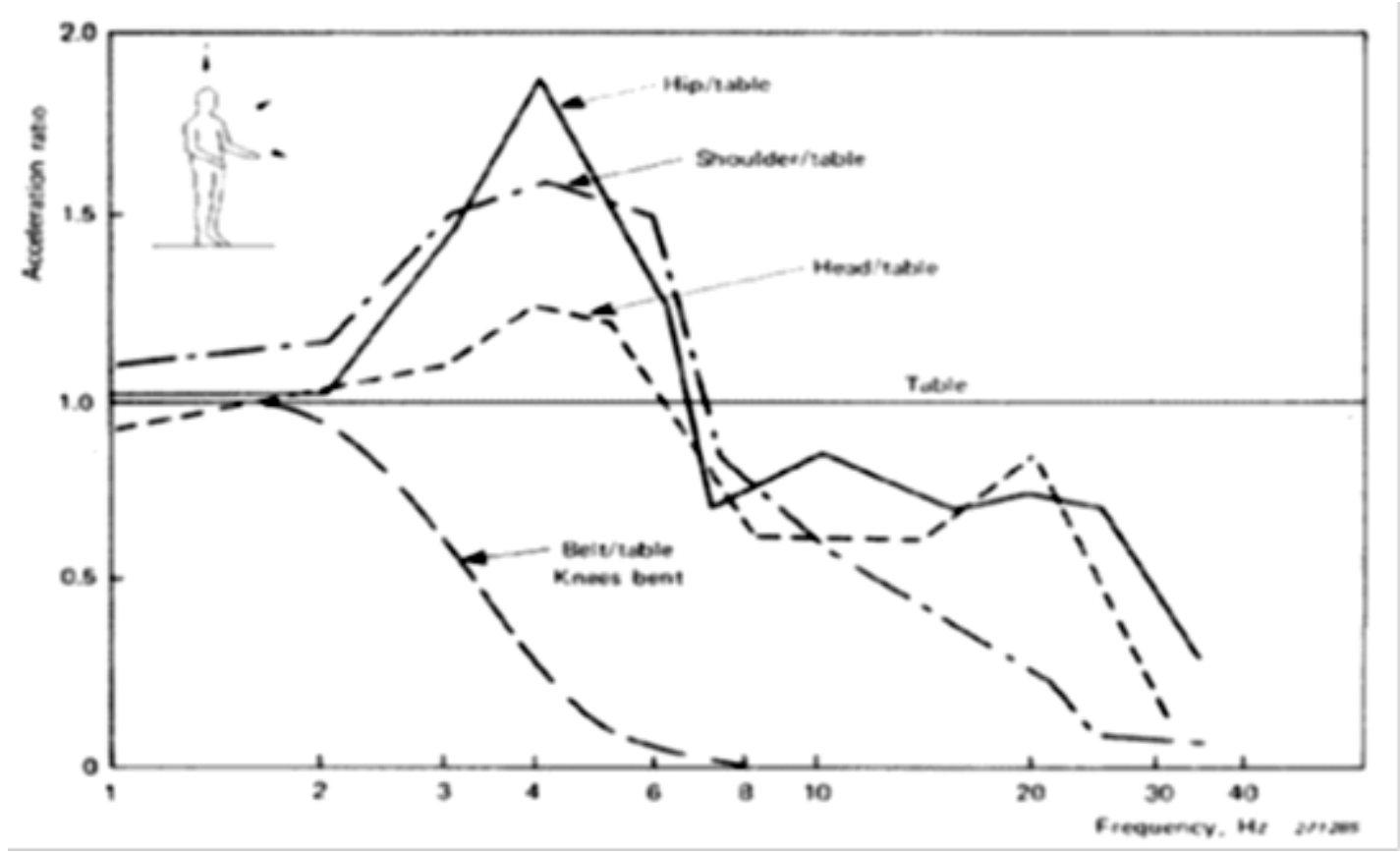

Fig. 5.a: Transmissibility of vertical vibration from table to human body, [17]

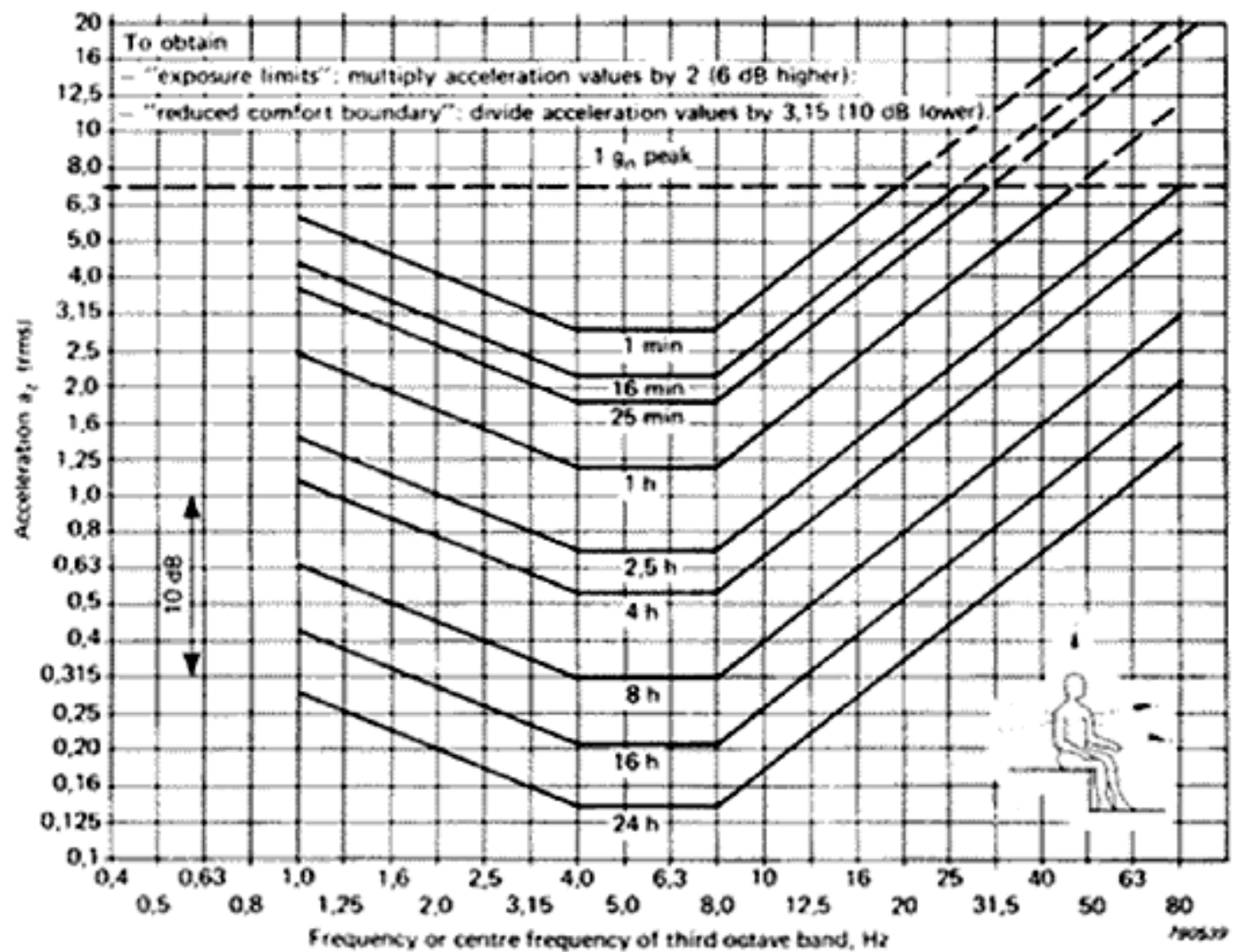

Fig. 5.b: Vertical vibration exposure criteria curves, [17] 


\section{Simulation Results}

The mathematical model of the system and the proposed sliding mode controller as defined in previous equation were simulated on computer by using the MATLAB and SIMULINK software package.

Fig. 3a shows the suspension travel of both the active and passive suspension systems due to a step dump for comparis on purposes. Fig. 6 illustrates clearly how the active suspension can effectively absorb early the vehicle vibration at $1.6 \mathrm{sec}$. while the passive system absorb at $2.25 \mathrm{sec}$. Moreover the wheel deflection is also smaller in the active suspension system. The body acceleration in the active suspension system is reduced significantly, which guarantee better ride comfort. The corresponding controller effort is illustrated at Fig.7.

Another common road inputs model assumed that the vehicle is to travel at a constant forward speed over

i) A random road profile, which is approximated by an integrated white noise input.

ii) the road profile $w(t)$ representing a single bump that acts as disturbance, given by cosine function:

$$
W(t)= \begin{cases}\propto(1+\cos 8 \pi t) \times 0.5 & t_{1} \leq t \leq t_{2} \\ 0 & \text { otherwise }\end{cases}
$$

Where $\alpha$ is the height of the bump, $t_{1}$ and $t_{2}$ are the lower and the upper time limit of the bump. Figure 8 shows the bump height for $10 \mathrm{~cm}$.
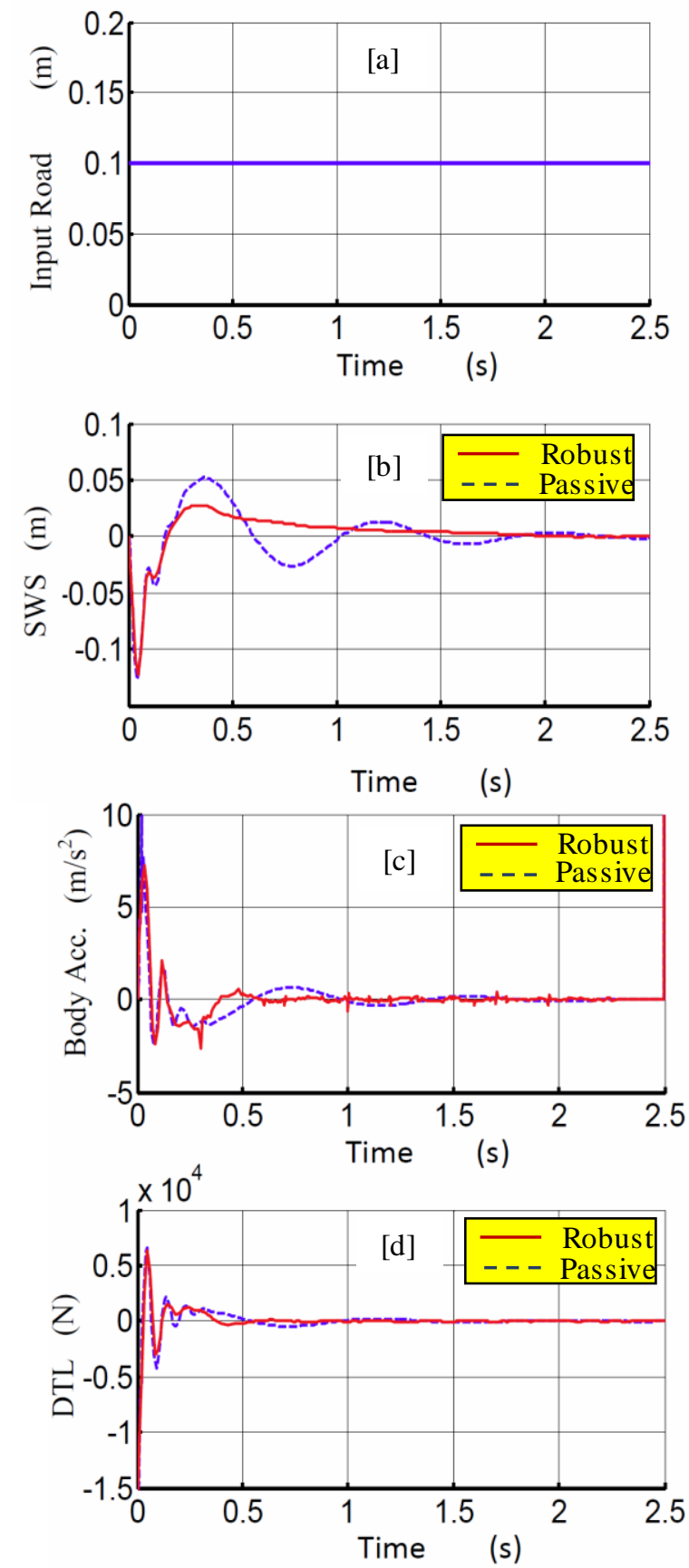

Fig. 6: The response of the suspension system with passive and robust Fuzzy control systems on smooth road

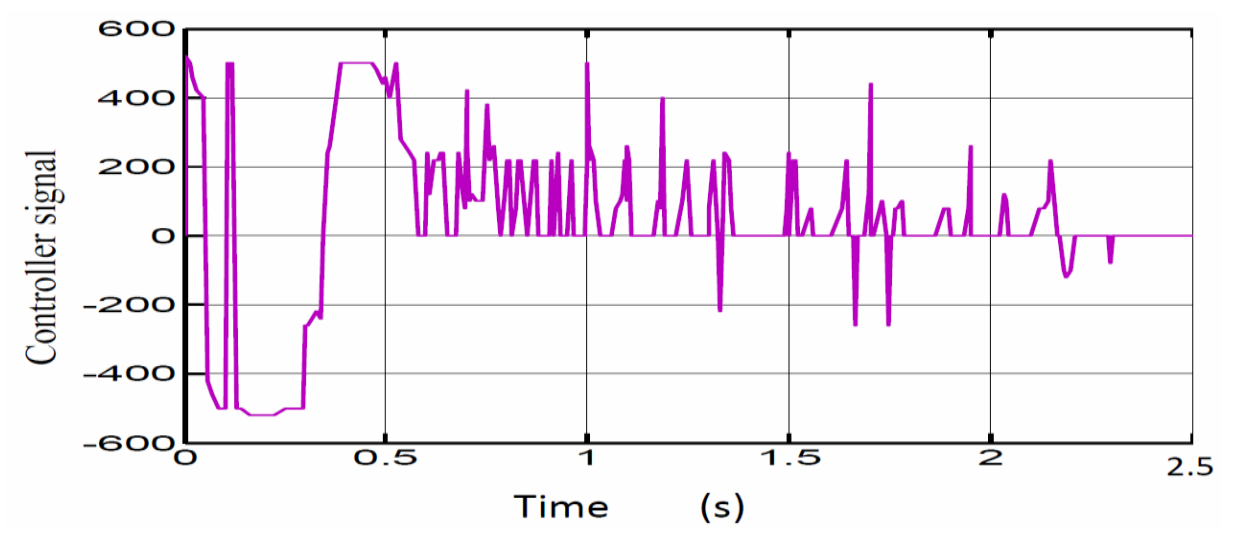

Fig. 7: Fuzzy control signal for smooth road 

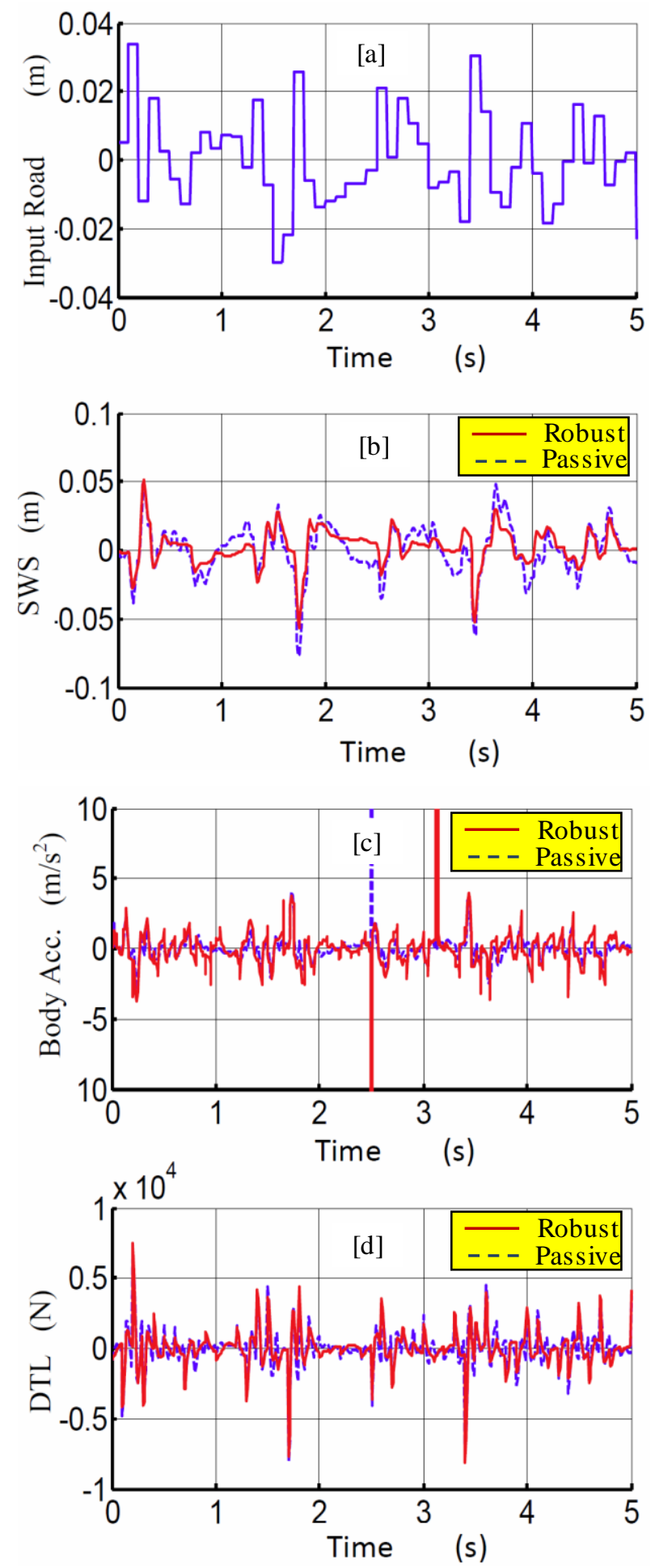

Fig. 8: The response of the suspension system with passive and robust Fuzzy control systems on real road roughness

In Figs. $(8,9)$ the results confirm the robustness of the proposed designed controller with the different road conditions. Therefore it is clear that the active suspension system improves the ride comfort while retaining the road handling characteristics, compared to the passive suspension system.
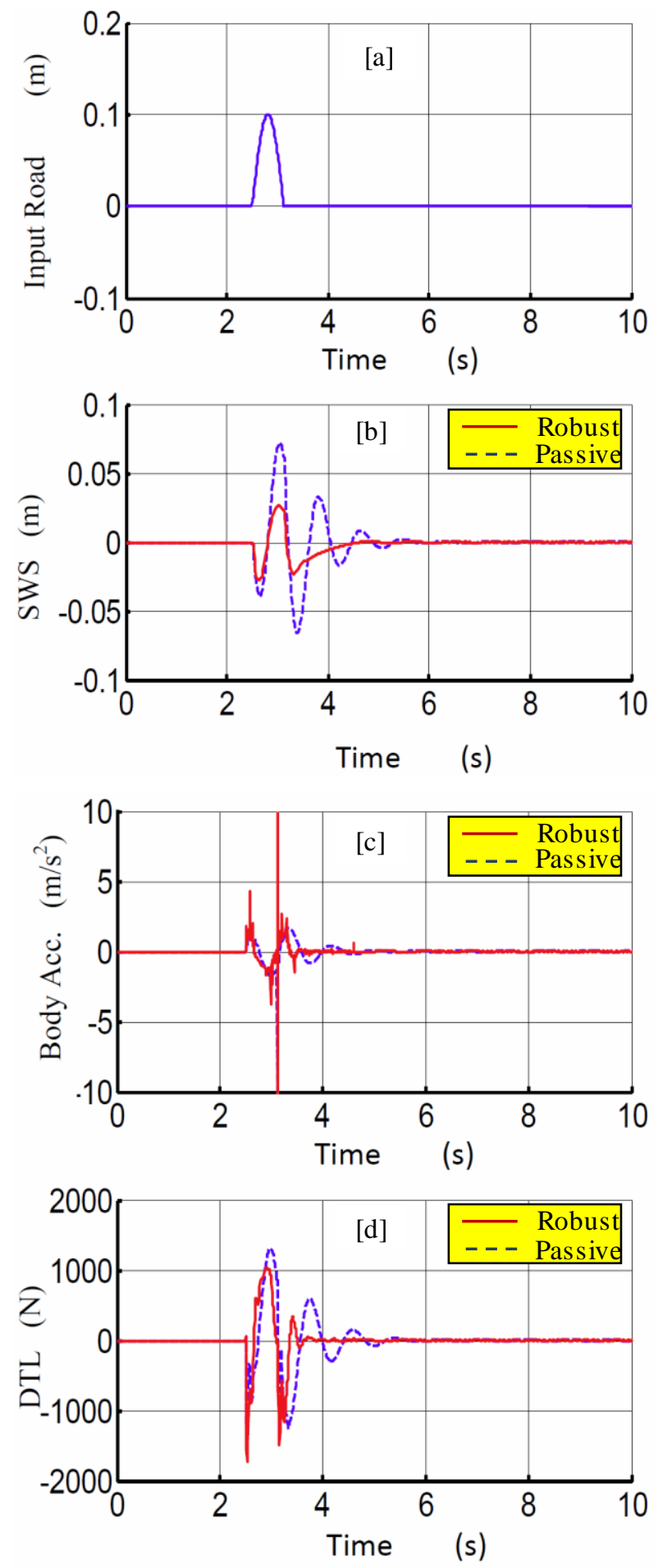

Fig. 9: The response of the suspension system with passive and robust Fuzzy control systems on cosine road profile

\section{Conclusion}

Many different control methods for suspension have been developed and research on improved control methods is continuing. Most of these approaches require system models, and some of them cannot achieve satisfactory performance under the changes of various road conditions, while soft computing methods like fuzzy control don't need a precise model. 
Computer simulations are performed to verify the feasibility of the proposed sliding mode fuzzy controller for the active suspension design by comparing with the passive suspension system. Based on simulation, it can be concluded that the sliding mode fuzzy control of active suspension system performs well as it is preferred to passive suspension system. This designed control is simple and easy to implement.

\section{References}

[1] Hac, A.: Suspension optimization of a 2-dof vehicle model using a stochasticoptimal control technique. Journal of Sound and Vibration. 100(3), 1985, pp 343-357.

[2] Narendra, K. and K. Parthasarathy, Identification and Control of Dynamical Systems Using Neural Network IEEE Transaction on Neural Network, 1990. 1(1): pp. 4-27. International Journal of Control and Automation Vol. 4 No. 2, June, 2011.

[3] Barron, M. B. and Powers, W. F., 1996, "The Role of Electronic Controls for Future Automotive Mechatronic Systems,"IEEE/ASME Trans. Mechatronics, Vol. 1, No. 1, pp. 80-88.

[4] Hrovat, D., and Hubbard, M.: A comparison between jerk optimal andacceleration optimal vibration isolation. Journal of Sound \& Vibration, 112, 2 , 1987, pp 201-210.

[5] Sharp, R.S., and Crolla, D.A.: Road vehicle suspension design - a review. Vehicle System Dynamics, 16, 1987, pp 167-192.

[6] Yue, C., Butsuen T., and Hedrick, J.K.: Alternative control laws for automotiveactive suspensions, ASME, Journal of Dynamic Systems, Measurement and Control, 111, 1989, pp 286-291.

[7] Chalasani, R.M.: Ride performance potential of active suspension systems-Part I: Simplified analysis based on a quarter-car model. ASME Monograph, AMD - vol. 80, DSC - vol. 2, 1986, pp 206-234.

[8] Hac, A., Youn, I., and Chen, H.H.: Control of suspension for vehicles with flexible bodies - Part I: active suspensions. ASME, Journal of Dynamic Systems, Measurement and Control, 118, 1996, pp 508-517.

[9] Rutledge, D.C., Hubbard, M., and Hrovat, D.: A two dof model for jerk optimalvehicle suspensions. Vehicle System Dynamics, 25, 1996, pp. 113-136.

[10] Lan Bo, Yu Fan, "Design and Simulation Analys is of LQG Controller of Active Suspension", Transactions of The Chinese Society of Agricultural Machinery, 2004, 1: pp.45-49.
[11] F Yu A Corolla, "An optimal self - tuning controller for an active suspension", Vehicle System Dynamic, 1998, 29: pp.51-65.

[12] Wilson D A, Sharp R S, Hassan S A, "Application of linear optimal control theory to the design of automobile suspensions". Vehicle System Dynamic, 1986, 15: pp.103 118.

[13] Lin, Kanella, kopoulos J S I, “Nonlinear design of active suspensions" IEEE Control Systems, 1997, 17(3): pp.45-49.

[14] ZHOU Ping, SUN Yue-dong, WANG Bing, "Simulation study on LQG controller for vehicle suspension system", Journal of University of Shanghai for Science and Technology, 2007, 5: pp.63-69

[15] M.M.M. Salam and Ay man A. Aly, "Fuzzy control of a quarter-car suspension system", International Conference in Mechanical Eng ineering, ICME, pp. 258-263, Tokyo, Japan, May 27-29, 2009.

[16] R.Vatankhah, M.Rahaeifard, and Aryaalasty," Vibration Control of Vehicle Suspension System Usingadaptive Critic-Based Neurofuzzy Controller", Proceeding o/the 6th International Symposium on Mechatronics and its Applications (ISMA09), Sharjah, UAE, March 24-26, 2009.

[17] ISO/DIS 5349 \& ISO 2631 - 1978, human sensitivity band.

Authors' Profile

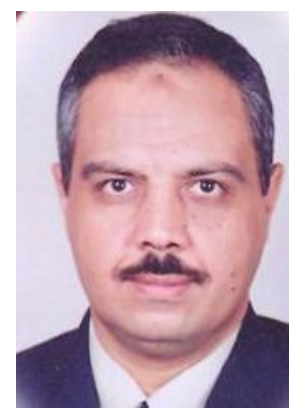

Associate Prof. Dr. Ayman A. Aly B.Sc. with excellent honor degree (top student), 1991 and M.Sc. in Sliding Mode Control from Mech., Eng., Dept., Assiut University, Egypt, 1996 and PhD. in Adaptive Fuzzy Control from Yamanashi University, Japan, 2003.

Nowadays, he is the head of Mechatronics Section at Taif University, Saudi Arabia since 2008. Prior to join ing Taif University, He is also one of the team who established the "Mechatronics and Robotics Engineering" Educational Program in Assiut University in 2006. He was in the Managing and Implementation team of the Project "Development of Mechatronics Courses for Undergraduate Program" DMCUP Project-HEEPF Grant A-085-10 Ministry of Higher Education - Egypt, 2004-2006.

The international biographical center in Cambridge, England selected Ayman A. Aly as international educator of the year 2012. Also, Ayman A. Aly was selected for inclusion in Marquis Who's Who in the World, 30 ${ }^{\text {th }}$ Pearl Anniversary Edition, 2013. 
In additions to 5 text books, Ayman A. Aly is the author of more than 60 scientific papers in Refereed Journals and International Conferences. He supervised some of MSc and PhD Degree Students and managed a number of funded research projects.

Prizes and scholarships awarded: The prize of Prof. Dr. Ramadan Sadek in Mechanical Engineering (top student), 1989, The prize of Prof. Dr. Talet Hafez in Mechanical Design 1990, Egyptian Government Scholarship 1999-2000, Japanese Government Scholarships (MONBUSHO), 2001-2002 and JASSO, 2011. The prize of Taif University for scientific research, 2012 and the prize of Taif University for excellence in scientific publishing, 2013.

How to cite this paper: Ayman A. Aly,"Robust Sliding Mode Fuzzy Control of a Car Suspension System", International Journal of Information Technology and Computer Science(IJITCS), vol.5, no.8, pp.46-53, 2013. DOI: 10.5815/ijitcs.2013.08.05 